\title{
Analysis and Implementation of a Half Bridge Class-DE Rectifier for Front-End ZVS Push-Pull Resonant Converters
}

\author{
Chainarin Ekkaravarodome ${ }^{\dagger}$ and Kamon Jirasereeamornkul ${ }^{*}$ \\ 'Dept. of Instrumentation and Electronics Engineering, King Mongkut's University of Technology North Bangkok, \\ Bangkok, Thailand \\ "Dept. of Electronic and Telecommunication Engineering, King Mongkut's University of Technology Thonburi, \\ Bangkok, Thailand
}

\begin{abstract}
An analysis of the junction capacitance in resonant rectifiers which has a significant impact on the operating point of resonance circuits is studied in this paper, where the junction capacitance of the rectifier diode is to decrease the resonant current and output voltage in the circuit when compared with that in an ideal rectifier diode. This can be represented by a simplified series resonant equivalent circuit and a voltage transfer function versus the normalized operating frequency at varied values of the resonant capacitor. A low voltage to high voltage push-pull DC/DC resonant converter was used as a design example. The design procedure is based on the principle of the half bridge class-DE resonant rectifier, which ensures more accurate results. The proposed scheme provides a more systematic and feasible solution than the conventional resonant push-pull DC/DC converter analysis methodology. To increase circuit efficiency, the main switches and the rectifier diodes can be operated under the zero-voltage and zero-current switching conditions, respectively. In order to achieve this objective, the parameters of the DC/DC converter need to be designed properly. The details of the analysis and design of this DC/DC converter's components are described. A prototype was constructed with a $62-88 \mathrm{kHz}$ variable switching frequency, a $12 \mathrm{~V}_{\mathrm{DC}}$ input voltage, a $380 \mathrm{~V}_{\mathrm{DC}}$ output voltage, and a rated output power of $150 \mathrm{~W}$. The validity of this approach was confirmed by simulation and experimental results.
\end{abstract}

Key words: Class-DE resonant rectifier, Push-pull resonant converter, Zero-current switching, Zero-voltage switching

\section{INTRODUCTION}

The push-pull resonant converter topologies in [1]-[3] were used in front-end DC/DC converters for distributed power generation based on battery-based energy storage or renewable energy systems [4]-[8] such as photovoltaic, fuel cells, wind turbines, etc. The push-pull resonant converter topology is suitable for unregulated low-voltage, $V_{L V D C}$, to high-voltage, $V_{H V D C}$, power conversion systems, which feed stand-alone and grid-connected inverters. The power conditioning system architecture consists of a first stage $\mathrm{DC} / \mathrm{DC}$ converter and a second stage $\mathrm{DC} / \mathrm{AC}$ inverter,

Manuscript received Jan. 13, 213; revised Apr. 30, 2013 Recommended for publication by Associate Editor Joung-Hu Park

Corresponding Author: chainarine@kmutnb.ac.th

Tel: +66-2555-2000, Fax: +66-2587-4846, KMUTNB

${ }^{*}$ Dept. of Electronic and Telecommunication Engineering, King Mongkut's University of Technology Thonburi, Thailand

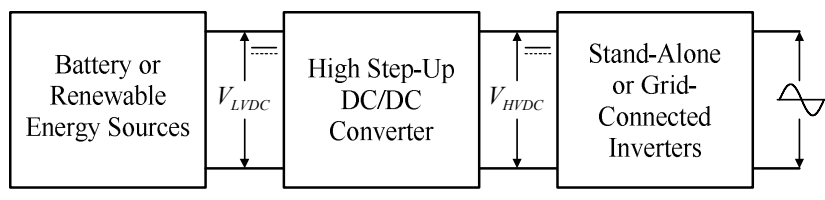

Fig. 1. Power conditioning system for renewable energy.

and is depicted in Fig. 1. The advantages of the push-pull resonant converters include their low component count and their ability to operate under zero voltage switching (ZVS) and zero current switching (ZCS) conditions [9], [10]. These advantages result in a higher overall system efficiency. For higher power applications, paralleling DC/DC converters is a better choice than paralleling too many power MOSFETs [11], [12]. There are active paralleling techniques with the current sharing control method. However, they make the controller more complicated and increase the controller cost. Current fed push-pull converters that use only an input 


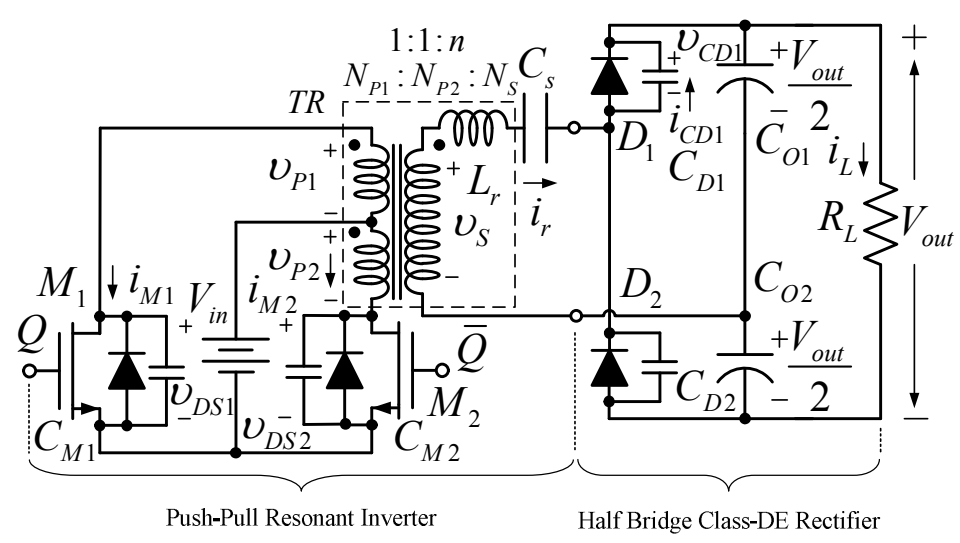

(a)

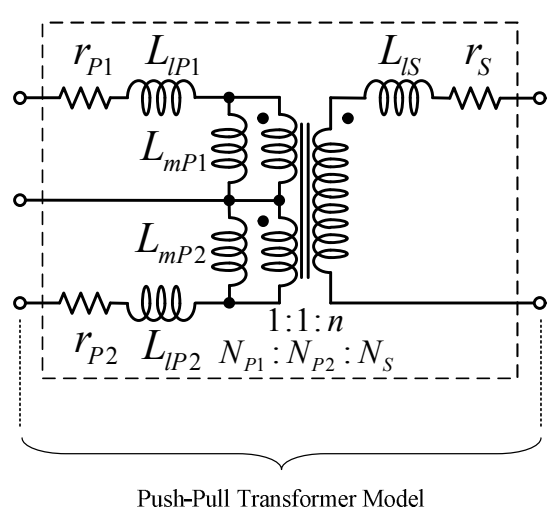

(b)

Fig. 2. Proposed ZVS push-pull resonant converter and transformer model.

inductor to obtain a small ripple in the input current have been presented [13], [14]. In reality, the junction capacitance of the rectifier diode of a push-pull resonant DC/DC converter cannot be neglected in high voltage and high-frequency operations. This is because the junction capacitance decreases the resonant current and output voltage. Due to the effect of the junction capacitance, it is very difficult to design all of the parameters for the converter [15-16]. The objective of this paper is to introduce an analysis of the junction capacitance in a half bridge rectifier diode which has a significant impact on the operating point of the resonance circuit. This is accomplished by using the principle of a half bridge class-DE rectifier with a push-pull resonant converter. The proposed scheme ensures more accurate results and provides a more systematic and feasible solution. The effects of the commutation of the transformer magnetizing current, the drain-source junction capacitance, the leakage inductance of the transformer, the resonant capacitance, the power MOSFETs and the power diodes can be turned on under the ZVS and turned off under the ZCS conditions, respectively. In order to achieve this objective, the parameters of the DC/DC converter need to be designed properly and the details of analysis and design of this DC/DC converter's components need to describe.

This paper is divided into six sections. In Section II, the circuit description is presented. In Section III, an analysis of the junction capacitance in the half bridge class-DE resonant rectifier for a ZVS push-pull resonant converter is presented. The design procedure for the components is reported in Section IV. Simulation and experimental results to support the theoretical analysis are presented in Section V. Some conclusions are given in Section VI.

\section{CIRCUIT DESCRIPTION}

Figure 2(a) illustrates the circuit of the proposed ZVS push-pull resonant converter with a half bridge class-DE resonant rectifier studied in this paper. It consists of a high-frequency center-tapped transformer $T R$, and has a center-tap at the primary winding of the push-pull type converter. The ZVS push-pull resonant converter is composed of bidirectional two-quadrant switches, $M_{1}$ and $M_{2}$, with a duty ratio of nearly 0.5 . Each switch is composed of a transistor and an anti-parallel diode. The switch can conduct either positive or negative current. The output voltage regulation is controlled by varying the operating frequency. The resonant inductor, $L_{r}$, consists of the secondary leakage inductor of the high-frequency transformer, $L_{l S}$, and two additional primary leakage inductors, $L_{l P 1}$ and $L_{l P 2}$. It is:

$$
L_{r}=\left(L_{l P 1}+L_{l P 2}\right)\left(\frac{n}{2}\right)^{2}+L_{l S}
$$

The value of the leakage inductor of the high-frequency transformer depends on the physical conditions [17] such as the magnetic material, air gap size, winding, etc. The equivalent circuit of the transformer is illustrated in Fig. 2(b), where the parameter values of the transformer are measured by an LCR meter. However, the magnetizing inductor of the transformer is very large. Thus the magnetizing current can be neglected. The resonant capacitor, $C_{r}$, is relatively the series capacitor, $C_{s}$, and the junction capacitors, $C_{D}=C_{D 1}=C_{D 2}$ of half bridge class-DE resonant rectifier diode. $L_{r}$ and $C_{r}$ are employed to achieve soft switching operation. The class-DE rectifier makes the output voltage equal to twice the peak output of the transformer by a two bulk-filter capacitors, $C_{O}=C_{O 1}=C_{O 2}$, where capacitor $C_{O}$ is large enough. Therefore, the output voltage, $V_{\text {out }}$, can be considered as constant and is supplies a load resistor, $R_{L}$. The series circuit, $L_{r}-C_{s}$, is fed by the square-wave output voltage of the secondary side of the high-frequency transformer and converted to a high-frequency current source to drive the half bridge class-DE resonant rectifier. 


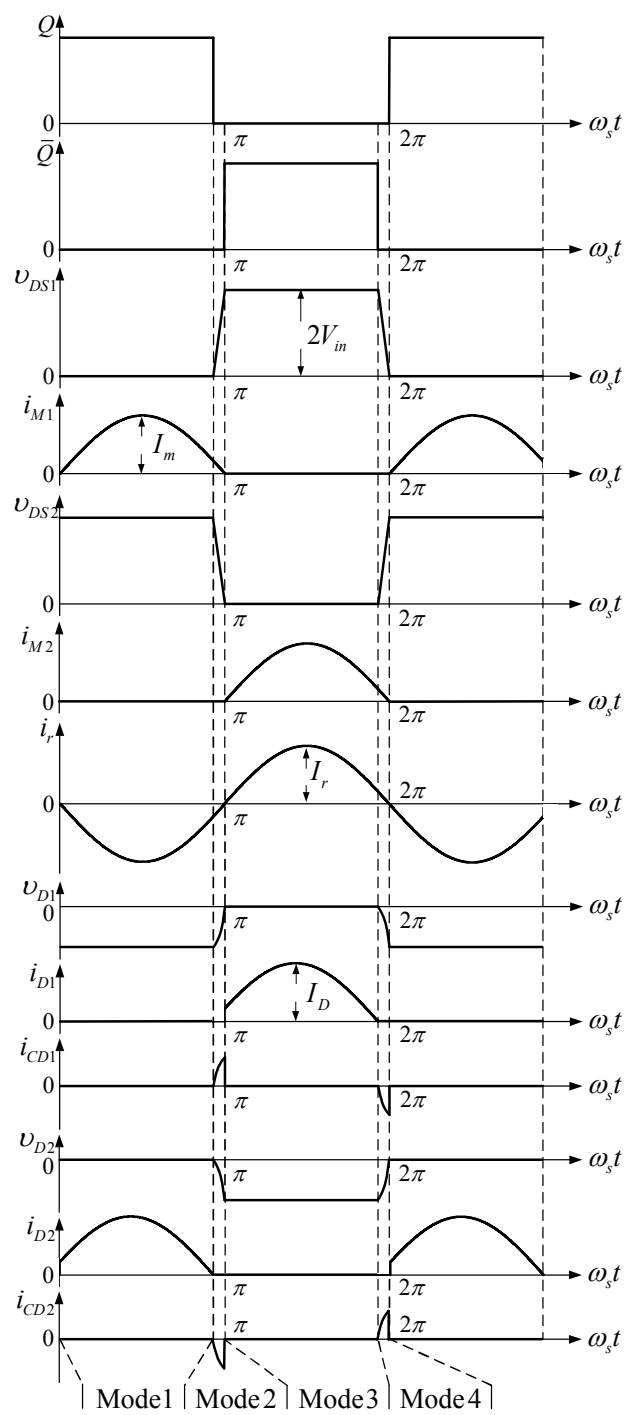

Fig. 3. Key waveforms of the proposed push-pull converter.

\section{ANALYSIS OF THE JUNCTION CAPACITANCE IN HALF BRIDGE ClASS-DE RECTIFIER DIODES}

The principle of operation of the half bridge class-DE rectifier with a push-pull resonant converter is explained by the waveforms shown in Fig. 3. The main switches and the rectifier diodes can operate under ZVS and ZCS conditions, respectively. It is reasonable to consider the transformer secondary side as a sinusoidal current source $i_{r}$, which is also the input current source of the half bridge class-DE rectifier. The operation of the proposed converter can be divided into four modes. The circuit schemes of the operating modes are depicted in Fig. 4. A detailed analysis of the complete operation including the four modes is described as follows:

Mode 1: In this mode, depicted in Fig. 4(a), the junction capacitor voltage of switch $M_{1}$ is completely discharged and $v_{D S 1}$ decreases to zero. Then switch $M_{1}$ is turns on under the
ZVS condition by commutation of the transformer magnetizing current and drain-source junction capacitance. At the same time, the junction capacitor voltage $v_{D S 2}$ of switch $M_{2}$ is charged from zero to $2 V_{i n}$. In the secondary side, diode $D_{2}$ turns off under the zero-current condition by current $i_{D 2}$ through the rectifier diode by the series resonant circuit $L_{r}-C_{r}$.

Mode 2: This mode is the commutation time of the converter. Switches $M_{1}$ and $M_{2}$ are turned off. The junction capacitor between the drain-source of switch $M_{1}, C_{M 1}$, charges voltage $v_{D S 1}$ until it is increased to $2 V_{\text {in }}$ and the junction capacitor between the drain-source of switch $M_{2}$, $C_{M 2}$, discharges voltage $v_{D S 2}$ until it is reduced from $2 V_{i n}$ to zero. Simultaneously, the half bridge rectifier junction capacitor $C_{D 1}$ of diode $D_{1}$ discharges to zero and junction capacitor $C_{D 2}$ of diode $D_{2}$ charges from zero until its voltage reaches $-V_{\text {out }}$ as shown in Fig. 4(b).

Mode 3: Figure 4(c) shows that junction capacitor voltage of switch $M_{1}$ is completely charged and $v_{D S 1}$ increases to $2 V_{i n}$. Then $M_{1}$ is turned off under the zero-current condition. Switch $M_{2}$ begins conducting. Current $i_{M 2}$ through switch $M_{2}$ at primary side of the transformer operates at zero-voltage. At the same time, diode rectifier $D_{1}$ of the class-DE rectifier turns off under the zero-current condition by current $i_{D 1}$ through the rectifier diode.

Mode 4: In Fig. 4(d), both switches $M_{1}$ and $M_{2}$ are turned off, the junction capacitor between the drain-source of switch $M_{1}, C_{M 1}$, discharges voltage $v_{D S 1}$ from $2 V_{i n}$ until its voltage reduces to zero. The junction capacitor between the drain-source of switch $M_{2}, C_{M 2}$, charges voltage $v_{D S 2}$ until it is increased to $2 V_{i n}$. Simultaneously, at the half bridge rectifier, junction capacitor $C_{D 1}$ of diode $D_{1}$ is charged until its voltage reaches $-V_{\text {out }}$ and junction capacitor $C_{D 2}$ of diode $D_{2}$ discharges its voltage to zero. Then, $D_{2}$ turns off under zero-current.

It should be noted that the circuits in Fig. 4(b) and (d), effects the commutation of the transformer magnetizing current and the drain-source junction capacitances, $C_{M 1}$ and $C_{M 2}$ of switches, $M_{1}$ and $M_{2}$. The power MOSFETs can be turned on under ZVS, when the voltage of the parasitic drain-source capacitor falls to zero. However, the switch must be turned on before $v_{S}(t)$ is increased to $V_{\text {out }} / 2$. The parasitic drain-source capacitor is charged again to exceed zero when $v_{S}(t)$ is equal to $V_{\text {out }} / 2$. Thus the main switch is not operated under ZVS. Therefore, the dead time in this proposed push-pull resonant converter is largely from operating modes 2 and 4 . The analysis of the junction capacitance in the half bridge class-DE resonant rectifier for push-pull ZVS resonant 
converters is demonstrated by the equivalent circuit, as shown in Fig. 5. The diode, $D_{1}$, of the half bridge class-DE resonant rectifier operates during the positive half-cycle of the high-frequency transformer secondary side square-wave voltage, while the equivalent circuits of secondary side of the high-frequency transformer are modeled by a squarewave voltage source, $v_{S}$. The fundamental component is $v_{S}(t)=V_{S} \sin \omega_{s} t$, where $\omega_{s}$ is the switching angular frequency and the diode, $D_{2}$, operates during the negative half-cycle. The equivalent circuit describing the impact of the junction capacitance of the half bridge class-DE resonant rectifier diode in high output voltage and high switching frequency

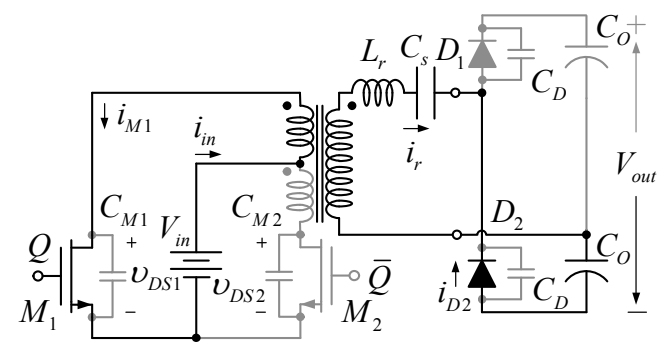

(a) Mode 1

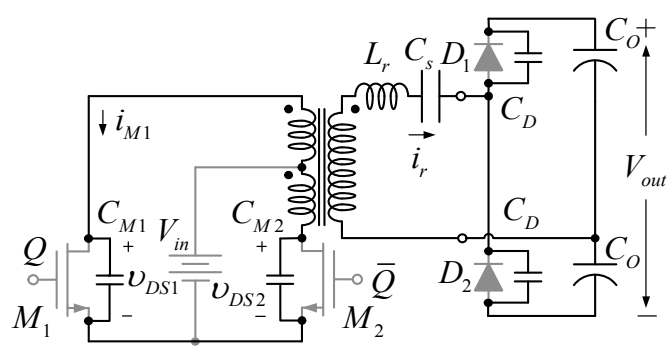

(b) Mode 2

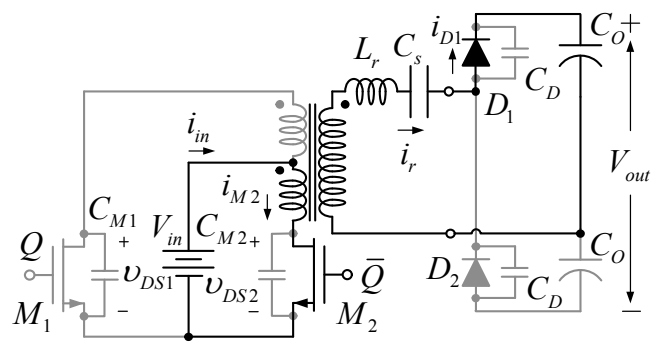

(c) Mode 3

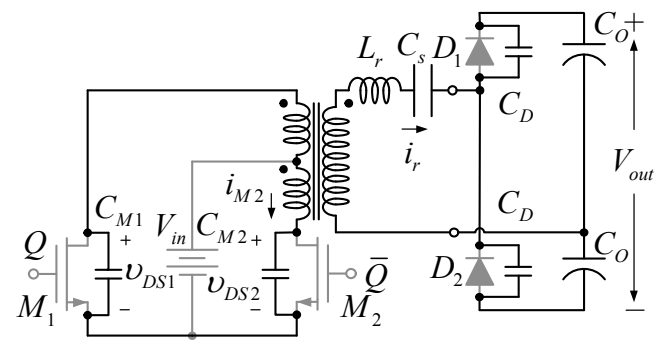

(d) Mode 4

Fig. 4. The operation mode of the proposed circuit.

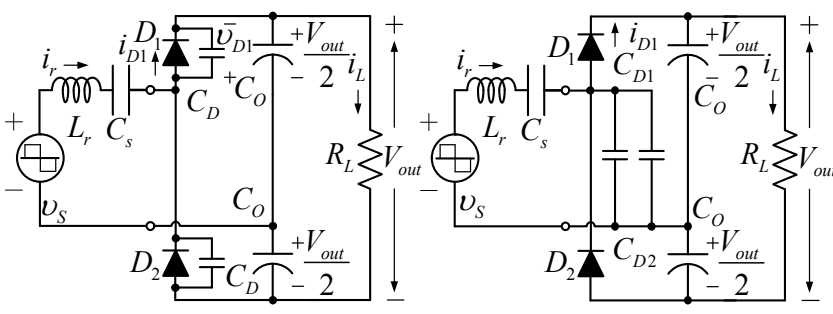

(a)

(b)

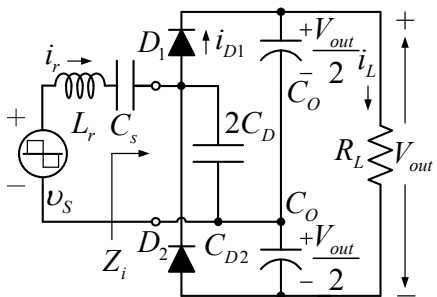

(c)

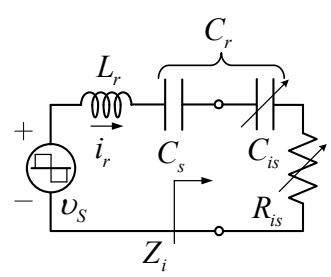

(e)

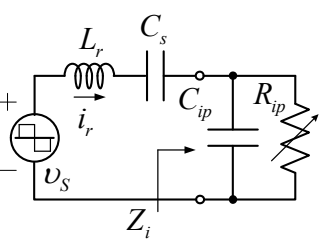

(d)

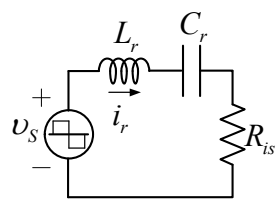

(f)

Fig. 5. The equivalent circuit describing the impact of the junction capacitance of the half bridge class-DE rectifier diode.

operations is shown in Fig. 5(a). Because the two dc voltage sources, $V_{\text {out }} / 2$, appears as a short circuit to the ac component, the junction capacitors, $C_{D 1}$ and $C_{D 2}$, are interchangeable, as shown in Fig. 5(b).

In this circuit, capacitor $C_{D E 1}$ is connected in parallel with capacitor $C_{D 2}$ and they can be combined into one capacitor $2 C_{D}=C_{D 1}+C_{D 2}$, as shown in Fig. 5(c). Figure 5(d) illustrates the model of the half bridge class-DE rectifier with a push-pull resonant converter. The input impedance of the class-DE rectifier is represented by a parallel $R_{i p}-C_{i p}$ circuit, which can then be converted into a series combination of the input resistor, $R_{i s}$, and the input capacitor, $C_{i s}$, based on the principle of the half bridge class-DE rectifier [18-20], as shown in Fig. 5(e). However, the value of the input capacitor, $C_{i s}$, of the half bridge class-DE rectifier depends on the junction capacitance in rectifier diode, $C_{D}$, which has a significant impact on the operating point of the resonance circuit, as shown in Fig. 5(f). Hence, the normalized input impedance of the half bridge class-DE rectifier can be described by:

$$
Z_{i}^{\prime}=\omega_{s} 2 C_{D} Z_{i}=R_{i s}^{\prime}-j X_{C i s}^{\prime}
$$

where $R_{i s}^{\prime}$ and $X_{C i s}^{\prime}$ are the normalized resistance and reactance which can be obtained by: 


$$
\begin{gathered}
R_{i s}^{\prime}=\frac{8 R_{L}^{\prime}}{\left(2 \pi+R_{L}^{\prime}\right)^{2}} \\
X_{C i s}^{\prime}=\left|\sqrt{\frac{8 R_{L}^{\prime}}{\pi}}\left(\frac{2 \pi-R_{L}^{\prime}}{\left(2 \pi+R_{L}^{\prime}\right)^{2}}\right)-\frac{1}{\pi} \cos ^{-1}\left(\frac{2 \pi-R_{L}^{\prime}}{2 \pi+R_{L}^{\prime}}\right)\right|
\end{gathered}
$$

The series capacitors $C_{s}-C_{i s}$ circuit is replaced by an equivalent capacitor, which is represented by $C_{r}=$ $C_{s} C_{i s} /\left(C_{s}+C_{i s}\right)$, as shown in Fig. 5(f). As a result, the junction capacitance in the half bridge class-DE resonant rectifier diode is highly important because of the effects of the resonance, which ensures more accurate results than the push-pull resonant converters reported previously [13-14]. The plots of the magnitude of the AC/DC voltage transfer function $V_{\text {out }} / V_{S}$ versus the operating frequency $f_{s} / f_{r}$ at varied values of the resonant capacitor, $C_{r}$, are shown in Fig. 6 . It can be seen the impact of the junction capacitance of the rectifier diode cannot be neglected, because the junction capacitance is to decrease the output voltage of the proposed circuit. The range of $Q_{L}$ is from 1.5 to 0.02 . With the above design, the operating region of the converter is shown as the shaded area in Fig. 7. It can be seen from the operating region that under a light load, the switching frequency needs to increase a great deal to keep the output voltage regulated. This is a main drawback for series resonant converters. Thus the push-pull DC/DC converter proposed in this paper is suitable for a narrow load range.

\section{Design PROCEDURE}

The design of the proposed ZVS push-pull resonant converter with a half bridge class-DE rectifier can be functionally divided into two parts: the ZVS push-pull converter and the ZCS half bridge class-DE rectifier. The design procedure for the ZVS push-pull resonant converter with the effect of the junction capacitance, by using the principle of the class-DE resonant rectifier is determined as follows:

1. Chooses the output voltage, $V_{\text {out }}$, and the maximum output power, $P_{\text {out }}$, and then calculate the minimum load, $R_{\text {Lmin }}$.

2. Find the loaded-quality factor, $Q_{L}$, value by assuming that the switching frequency, $f_{s}$, is approximately equal to the resonant frequency, $f_{r}$, for full power.

3. Find the input impedance of the half bridge class-DE resonant rectifier, $Z_{i f f}=R_{i s_{f}}-j X_{\text {Cis } f}$.

4. Find the resonant inductor, $L_{r}$, which is composed of the secondary leakage inductor, $L_{l S}$, and two additional primary leakage inductors, $L_{l P 1}$ and $L_{l P 2}$.

5. Find the resonant capacitor, $C_{r}$.

6. Find the series capacitor, $C_{s}$, which is related to the resonant capacitor, $C_{r}$, and the input capacitance, $C_{i s}$, of half bridge class-DE resonant rectifier.

7. Find the value of output capacitor, $C_{O}$, choose the ripple

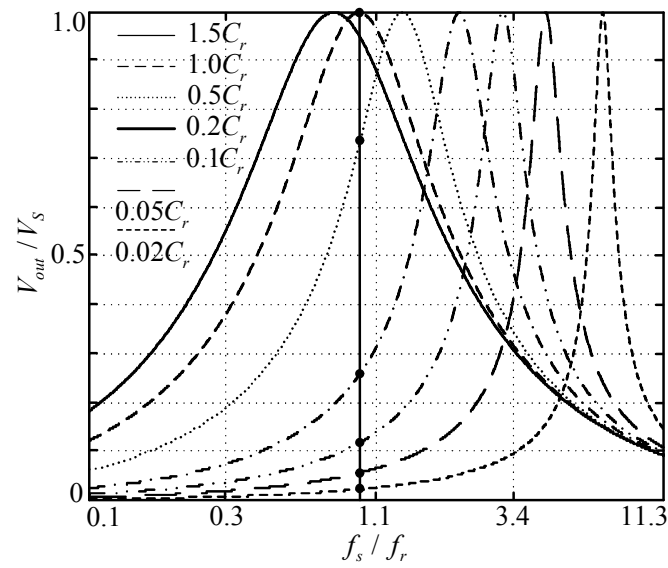

Fig. 6. $V_{\text {out }} / V_{S}$ versus $f_{s} / f_{r}$ at varied values of resonant capacitor.

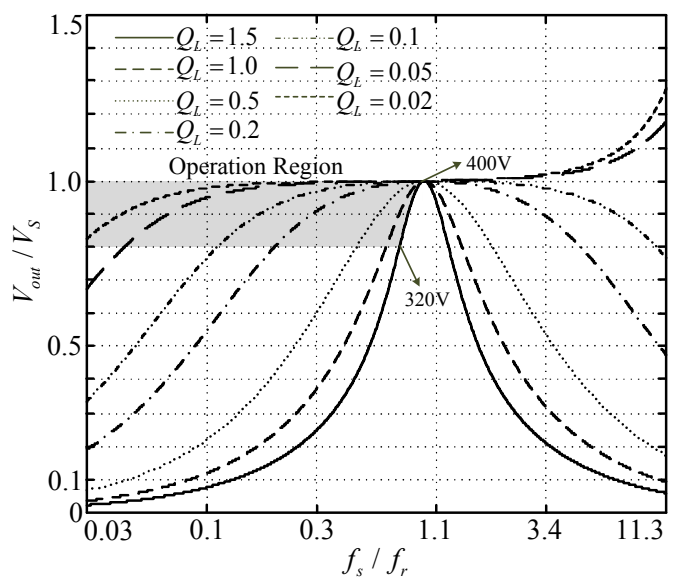

Fig. 7. $V_{\text {out }} / V_{S}$ versus $f_{s} / f_{r}$ at varied values of quality factor.

voltage and assume that the $C_{O}$ is large enough. Thus $V_{\text {out }}$ can be considered as a constant.

8. Finally, the transformer design of the proposed ZVS push-pull resonant converter with a half bridge class-DE resonant rectifier is the same as the pulse-width modulation (PWM) push-pull DC/DC converter.

\section{A. DC/DC Converter Design}

The equivalent circuit of the half bridge class-DE rectifier with the ZVS push-pull converter is shown in Fig. 5. For steady-state operation, where the operation at an $88 \mathrm{kHz}$ switching frequency, the input voltage is $V_{i n}=12 \mathrm{~V}_{\mathrm{DC}}$, the output voltage is $V_{\text {out }}=380 \mathrm{~V}_{\mathrm{DC}}$ and $R_{\text {Lmin }}$ is:

$$
R_{\text {Lmin }}=\frac{V_{\text {out }}^{2}}{P_{\text {outmax }}}=\frac{380^{2}}{150}=962.67 \Omega .
$$

where the maximum output power is $150 \mathrm{~W}$, the output voltage [18] can be described by (6) and the maximum value of the resonant current, $I_{r}$, is given by (19):

$$
V_{\text {out }}=\frac{I_{r} R_{\text {Lmin }}}{\pi+\omega_{S} C_{D} R_{\text {Lmin }}}
$$




$$
=\frac{1.24 \times 962.67}{\pi+\left(2 \pi \times 88 \times 10^{3} \times 10 \times 10^{-12} \times 962.67\right)}=379.33 \mathrm{~V} .
$$

Assume that $f_{s}=f_{r}$ at full power. The loaded-quality factor, $Q_{L}$, is then given by:

$$
\begin{aligned}
Q_{L} & =\frac{C_{S}+C_{i s}}{2 \pi f_{r} R_{i s} C_{S} C_{i s}}=\frac{2 \pi f_{r} L_{r}}{R_{i s}} \\
& =\frac{2 \pi \times 88 ? 0^{3} \times 336 ? 0^{-6}}{193.59}=0.96 .
\end{aligned}
$$

Under a full load, the input impedance of the half bridge class-DE resonant rectifier can be expressed as:

$$
Z_{i_{-} f}=R_{i s_{-} f}-j X_{C i s_{-} f}=193.59-j 7.96 \Omega,
$$

where:

$$
\begin{aligned}
R_{i s} & =\frac{2 R_{L}^{\prime}}{\pi f_{r} C_{D}\left(2 \pi+R_{L}^{\prime}\right)^{2}} \\
& =\frac{2 \times 0.0106}{\left(\pi \times 88 \times 10^{3} \times 10 \times 10^{-12}\right)(2 \pi+0.0106)^{2}}=193.59 \Omega .
\end{aligned}
$$

and:

$$
\begin{aligned}
C_{i s} & =\mid \frac{2 C_{D}}{\sqrt{\frac{8 R_{L}^{\prime}}{\pi}\left(\frac{2 \pi-R_{L}^{\prime}}{\left(2 \pi+R_{L}^{\prime}\right)^{2}}\right)-\frac{1}{\pi} \cos ^{-1}\left(\frac{2 \pi-R_{L}^{\prime}}{2 \pi+R_{L}^{\prime}}\right)} \mid} \\
& =\left|\frac{2 \times 10 \times 10^{-12}}{\sqrt{\frac{8 \times 0.0106}{\pi}}\left(\frac{2 \pi-0.0106}{(2 \pi+0.0106)^{2}}\right)-\frac{1}{\pi} \cos ^{-1}\left(\frac{2 \pi-0.0106}{2 \pi+0.0106}\right)}\right| \\
& =227.27 \mathrm{nF} .
\end{aligned}
$$

where $R_{L}^{\prime}=4 \pi f_{r} C_{D} R_{\text {Lmin }}=0.0106$ is the normalized effective load resistance. Hence, the resonant inductor is given by:

$$
L_{r}=\frac{Q_{L} R_{i s}}{2 \pi f_{r}}=\frac{0.96 \times 193.59}{2 \pi \times 88 \times 10^{3}}=336.11 \mu \mathrm{H}
$$

The resonant capacitor is obtained by:

$$
C_{r}=\frac{1}{2 \pi f_{r} Q_{L} R_{i s}}=\frac{1}{2 \pi \times 88 \times 10^{3} \times 0.96 \times 193.59}=9.73 \mathrm{nF} .
$$

However, to compensating the decrease in the resonant capacitance, $C_{r}$, due to the junction capacitance, $C_{i s}$, with an increase in the series capacitor, $C_{s}$, is given by:

$C_{s}=\frac{C_{i s} C_{r}}{C_{i s}-C_{r}}=\frac{227.27 \times 10^{-9} \times 9.73 \times 10^{-9}}{227.27 \times 10^{-9}-9.73 \times 10^{-9}}=10.16 \mathrm{nF}$.
Finally, the value of the output capacitor, $C_{O}$, is used for energy storage and to achieve a ripple voltage, $V_{\text {ripple }}$, of less than $2 \%$. Thus the value of the filter capacitor is given by:

$$
\begin{aligned}
C_{O} & \geq \frac{V_{\text {out }}}{2 f_{S} R_{\text {Lmin }} V_{\text {ripple }}} \\
& =\frac{380}{2 \times 88 \times 10^{3} \times 967.67 \times 7.6}=293.58 \mathrm{nF} .
\end{aligned}
$$

Therefore, a standard value of $1 \mu \mathrm{F}$ is selected for $C_{O}$.

\section{B. Conduction Loss Analysis}

The proposed circuit is composed of three major components. These three components are the power MOSFET, power diode, and push-pull transformer. The equivalent circuit of the proposed converter for conduction loss analysis is shown in Fig. 8. The MOSFETs are modeled by switches with the on-resistances, $r_{D S 1}$ and $r_{D S 2}$. The resistances, $r_{P 1}, r_{P 2}$, and $r_{S}$ represent the equivalent resistances of the physical primary and secondary leakage inductors, $L_{l P 1}$, $L_{l P 2}$ and $L_{l S}$ of the transformer, respectively. The power diodes are modeled by switches with the constant voltage source, $V_{F}$, and the on-resistances, $r_{D 1}$ and $r_{D 2}$. Therefore, the maximum value of the drain current, $I_{m}$, is given by (15). In testing the efficiency of the push-pull transformer under full power, it can be assumed that the total efficiency, $\eta$, was equal to 0.93. Consequently, the power loss in each MOSFET forward resistance, $r_{D S}$, is given by (16):

$$
\begin{gathered}
I_{\text {in }}=I_{m}=\frac{\pi P_{\text {out }}}{2 \eta V_{\text {in }}}=\frac{\pi \times 150}{2 \times 0.93 \times 12}=21.11 \mathrm{~A} . \\
P_{r D S}=\frac{I_{m}^{2} r_{D S}}{4}=\frac{21.11^{2} \times 4.5 \times 10^{-3}}{4}=501.34 \mathrm{~mW} .
\end{gathered}
$$

The converter employs (IRFP2907 International Rectifier) MOSFETs, each with an on-resistance, $r_{D S}$, of $4.5 \mathrm{~m} \Omega$. The power loss in the diodes, $D_{1}-D_{2}$, due to the forward voltage, $V_{D}=V_{D 1}=V_{D 2}$, is obtained as:

$$
P_{D B}=V_{D} I_{D}=\frac{V_{D} P_{\text {out }}}{V_{\text {out }}}=\frac{1.3 \times 150}{380}=513.16 \mathrm{~mW} .
$$

The half bridge rectifier was built using a (MUR840 Intersil) fast-recovery diode with a $p n$ junction diode $\left(V_{D}=1.3 \mathrm{~V}\right)$. The ESR of the primary leakage inductor is $r_{P}=r_{P 1}=r_{P 2}=$ $22.9 \mathrm{~m} \Omega$. Therefore, the conduction loss in the resonant inductor, $L_{P}=L_{P 1}=L_{P 1}$, is:

$$
P_{r p}=\frac{I_{m}^{2} r_{P}}{4}=\frac{21.11^{2} \times 22.9 \times 10^{-3}}{4}=2.48 \mathrm{~W} .
$$


TABLE I

Circuit Parameters of the Prototype

\begin{tabular}{lll}
\hline \hline Parameter & Symbol & $\begin{array}{c}\text { Value and } \\
\text { Part Number }\end{array}$ \\
\hline Input voltage & $V_{\text {in }}$ & $12 \mathrm{~V}_{\mathrm{DC}}$ \\
Output voltage & $V_{\text {out }}$ & $380 \mathrm{~V}_{\mathrm{DC}}$ \\
Maximum output power & $P_{\text {out }}$ & $150 \mathrm{~W}$ \\
Switching frequency & $f_{s}$ & $62-88 \mathrm{kHz}$ \\
Turns ratio & $N_{P 1}: N_{P 2}: N_{S}$ & $1: 1: 17$ \\
MOSFETs & $M_{1}, M_{2}$ & IRFP2907 \\
Fast recovery diodes & $D_{1}, D_{2}$ & $\mathrm{MUR} 840$ \\
Series capacitor & $C_{S}$ & $10.16 \mathrm{nF}$ \\
Diode junction capacitors & $C_{D 1}, C_{D 2}$ & $10 \mathrm{pF}$ \\
Bulk-filter capacitors & $C_{O 1}, C_{O 2}$ & $1 \mu \mathrm{F}$ \\
Resonant inductor & $L_{r}$ & $336 \mu \mathrm{H}$ \\
\hline \hline
\end{tabular}

The parasitic resistance of the secondary leakage inductor, $r_{S}$, is $640 \mathrm{~m} \Omega$, and the maximum value of the resonant current, $I_{r}$, is given by (19). Thus the conduction loss in the inductor, $L_{l S}$, is obtained by (20):

$$
\begin{aligned}
I_{r} & =\frac{V_{\text {out }}\left(\pi+2 \pi f_{r} C_{D} R_{\text {Lmin }}\right)}{R_{\text {Lmin }}} \\
& =\frac{380 \times\left(\pi+2 \pi \times 88 \times 10^{3} \times 10 \times 10^{-12} \times 962.67\right)}{962.67} \\
& =1.24 \mathrm{~A} .
\end{aligned}
$$

$P_{r s}=\frac{I_{r}^{2} r_{S}}{2}=\frac{1.24^{2} \times 640 \times 10^{-3}}{2}=492.03 \mathrm{~mW}$

Conduction losses due to the parasitic resistance in the all of capacitors are very small. Therefore, their affects were neglected.

\section{SimULATION AND EXPERIMENTAL RESULtS}

\section{A. Simulation Results}

The simulated output voltage versus the varied junction capacitance of the rectifier diode and the varied switching frequency are shown in Fig. 9 and 10, respectively. It can be seen that the impact of the junction capacitance of the rectifier diode cannot be neglected at high frequency and high voltage conditions, where the large junction capacitance of the rectifier diode and the high-frequency operation are to decrease the output voltage in the circuit. These issues can be solved by using the principle of the half bridge class-DE rectifier with a push-pull resonant converter. The proposed scheme can ensures more accurate results and provided a more systematic and feasible solution than the conventional resonant push-pull DC/DC converter analysis methodology.

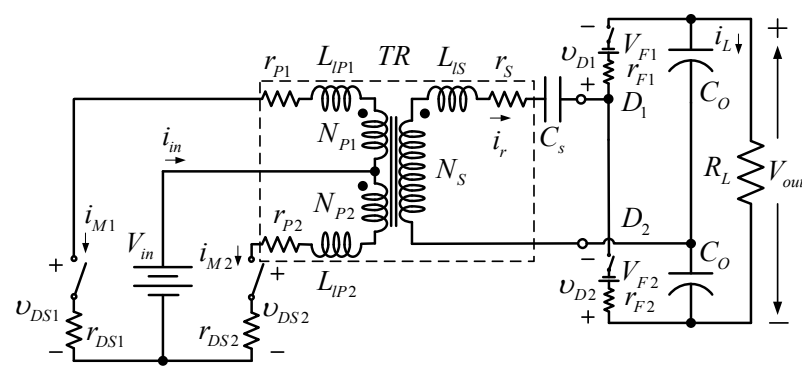

Fig. 8. Equivalent circuit of the proposed circuit.

Figure 11 depicts the output voltage versus the varied load resistance. It can be seen that the output voltage regulation is controlled by the frequency modulation technique. The simulated waveforms of the diode junction capacitance voltage and current of diode $D_{1}$, the drain-source voltage and drain current of MOSFET $M_{1}$, and the input current are shown in Fig. 12. They roughly match the key waveforms of the proposed push-pull converter shown in Fig. 3. Due to the effects of the commutation of the transformer magnetizing current and drain-source junction capacitances, $C_{M 1}$ and $C_{M 2}$, of switches, $M_{1}$ and $M_{2}$, the power MOSFETs can be turned on under the ZVS condition. The diode begins to turn off when its current reaches zero. The current passing through

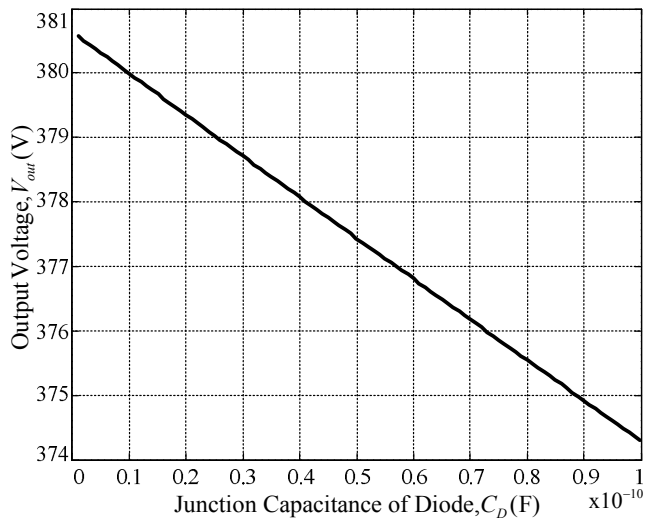

Fig. 9. Simulated output voltage versus varied junction capacitance of rectifier diode.

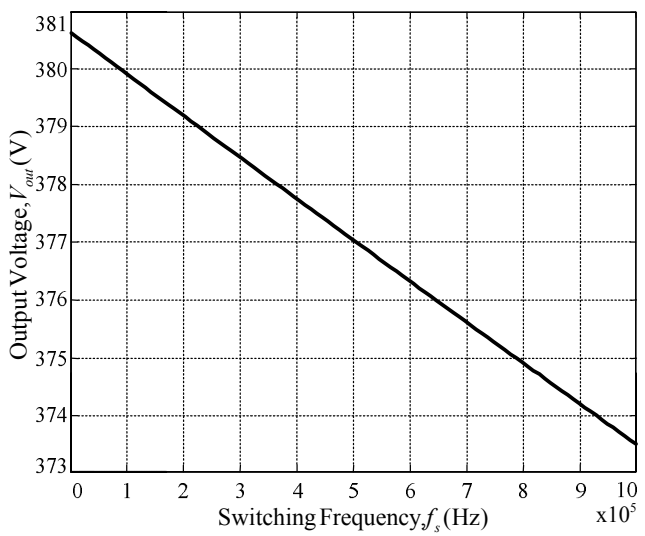

Fig. 10. Simulated output voltage versus varied switching frequency. 


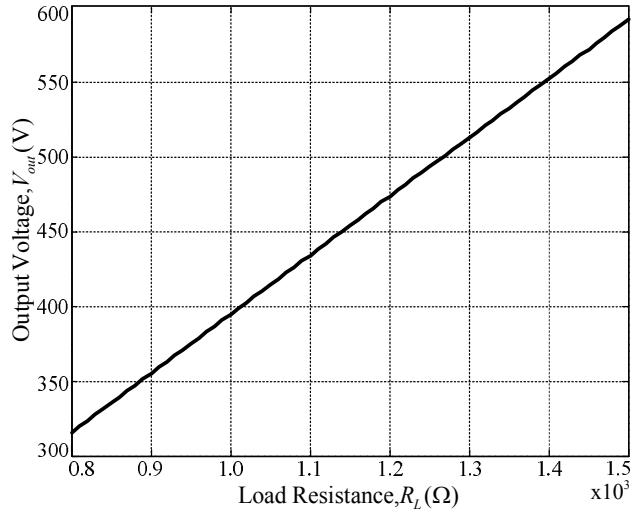

Fig. 11. Simulated output voltage versus varied load resistance.

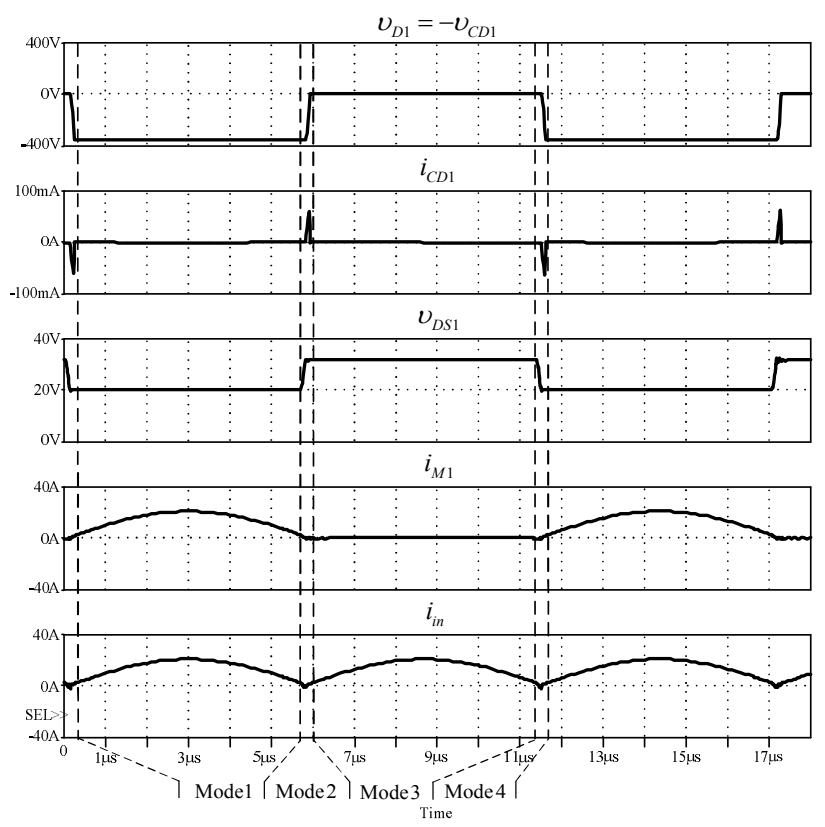

Fig. 12. The simulated waveforms of the junction capacitance diode voltage $v_{C D 1}$ and current $i_{C D 1}$ of diode $D_{1}$, drain-source voltage $v_{D S 1}$ and current $i_{M 1}$ of switch $M_{1}$, and input current $i_{i n}$.

the junction capacitances, $C_{D 1}$ and $C_{D 2}$, shapes the voltage across the diode in accordance with the equation $i_{C D 1,2}=C_{D 1,2} d\left(v_{C D 1,2}\right) / d t$. Because $i_{C D 1,2}$ is zero at turn-off, the diode turns off at a low $d v / d t$. The diode turns off at a low $d v / d t$ to reduce the turn-off switching loss and noise. Figure 13 shows the simulated resonant current waveforms of the ideal diode and non-ideal diode of the half bridge resonant rectifier. These waveforms show that the resonant current in the non-ideal diode of the half bridge resonant rectifier has to decrease the value when compared to the ideal diode. The higher value for the junction capacitance is the main drawback of this circuit.

\section{B. Experimental Results}

A prototype of the proposed half bridge class-DE resonant rectifier with a ZVS push-pull resonant converter was constructed using the component values obtained from the design procedure given above. The circuit parameters are presented in Table I. The switching frequency was varied at about $62-88 \mathrm{kHz}$. The input voltage was set to $12 \mathrm{~V}_{\mathrm{DC}}$. The waveforms of the input current and resonant current are shown in Fig. 14. These waveforms show that the input and resonant currents become close to sinusoidal. The waveforms of the switch voltage and switch current of $M_{1}$ are depicted in Fig. 15. Figure 16 illustrates the switch voltage and switch current waveforms of $D_{2}$ of the half bridge class-DE rectifier. It can be seen that the power MOSFETs and power diodes are

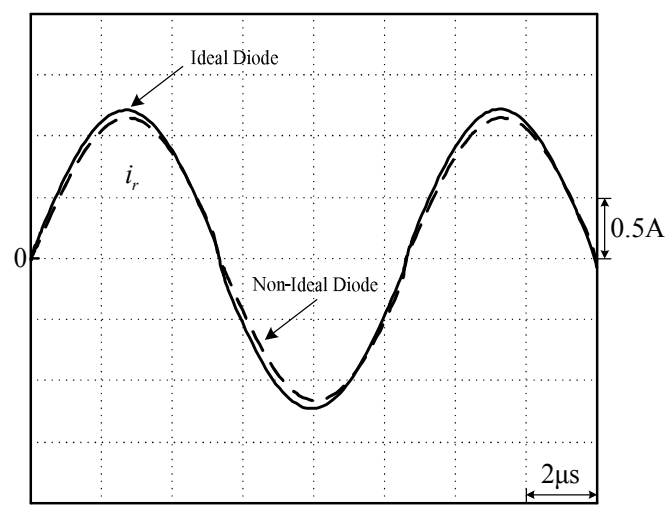

Fig. 13. Comparison of the simulated resonant current $i_{r}$ waveforms of the ideal and non-ideal diodes of the half bridge resonant rectifier.

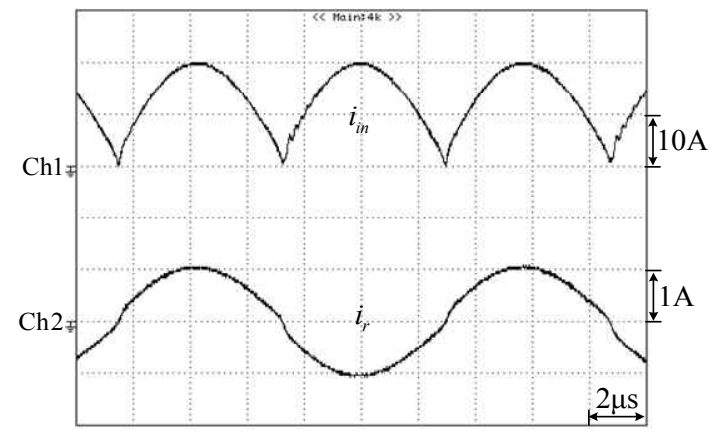

Fig. 14. Experimentations input current $i_{\text {in }}$ and resonant current $i_{r}$ waveforms.

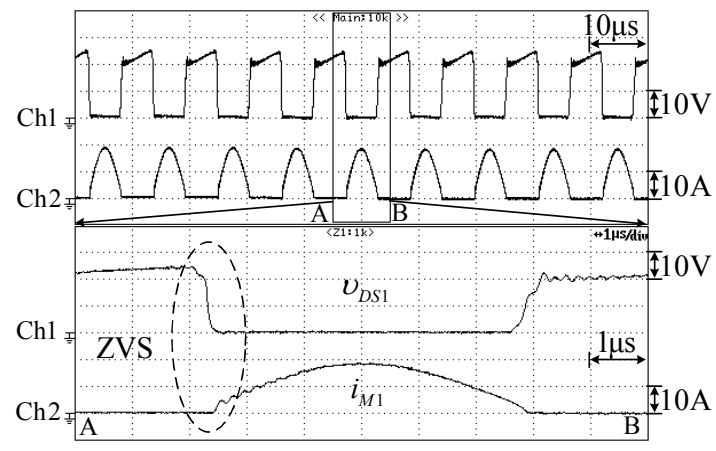

Fig. 15. Experimentations switch voltage and current waveforms of $M_{1}$, with the lower two waveforms as zoomed-in views of the top two waveforms. 


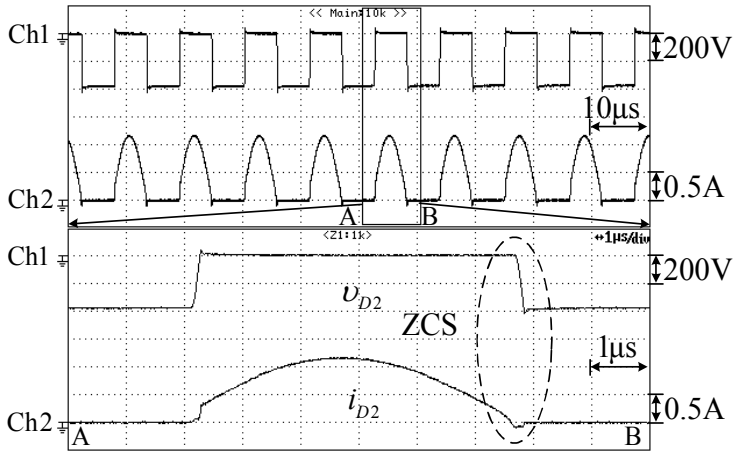

Fig. 16. The measured waveforms of the diode voltage $v_{D 2}$ and current $i_{D 2}$, with the lower two waveforms as zoomed-in views of the top two waveforms.

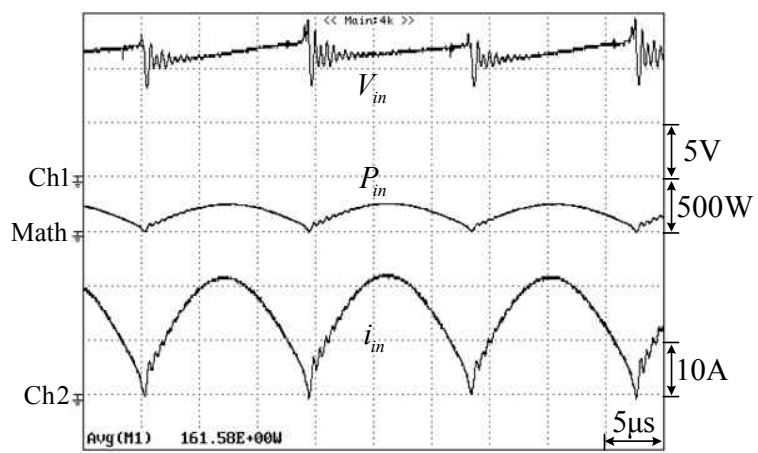

Fig. 17. Measured input voltage, current, and rated output power waveforms.

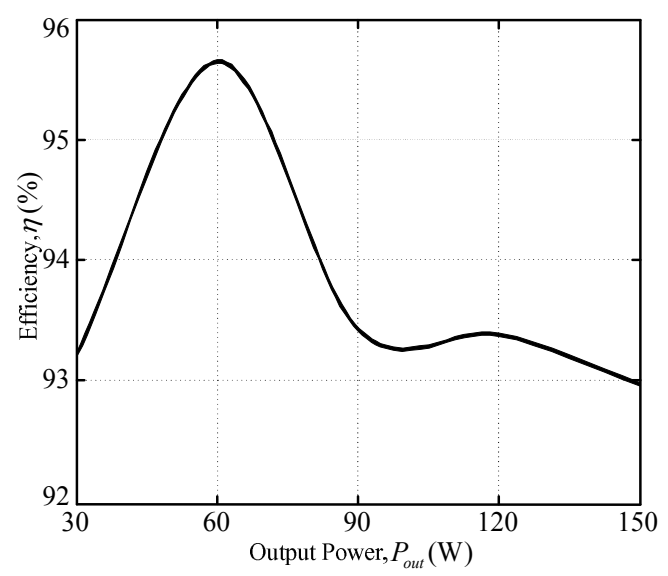

Fig. 18. Efficiency as a function of output power.

turned on under ZVS and turned off under ZCS conditions, respectively. This is due to the effects of the commutation of the transformer magnetizing current, the drain-source junction capacitance, the leakage inductance of the transformer, and the resonant capacitance. The measured efficiency of the class-DE rectifier with a ZVS push-pull converter was approximately $92.97 \%$ at full power, as shown in Fig. 17. Figure 18 shows the conversion efficiency versus the output power when the supplied load is changed from 30 to $150 \mathrm{~W}$. The maximum conversion efficiency was $95.63 \%$.

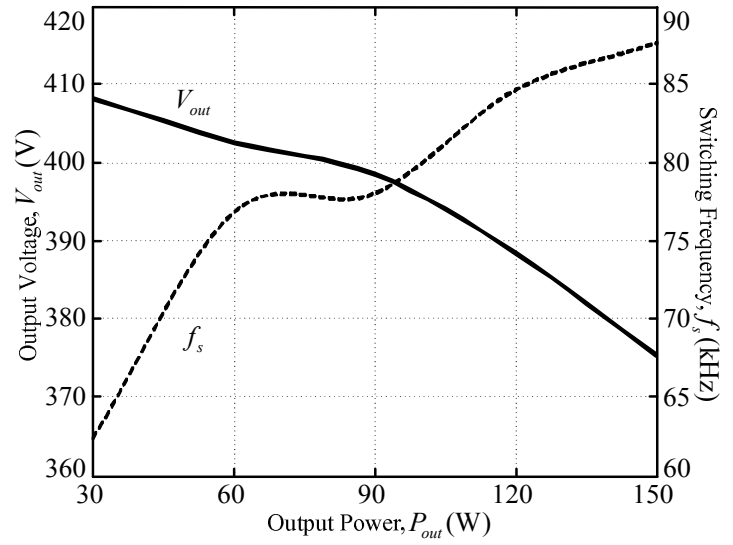

Fig. 19. Output voltage versus output power and varied switching frequency.

Because the maximum efficiency occurred in the high-frequency transformer, the core losses equal the copper losses. The min and max values of efficiency are slightly different. The relationship of the output power and the conversion efficiency, when the switching frequency was varied, is shown in Fig. 19. Thus the output voltage regulation is controlled by the frequency modulation mean. It can be shown that the low voltage to high voltage resonant push-pull DC/DC converter proposed in this paper is suitable for a narrow load range.

\section{CONCLUSION}

In this paper, the junction capacitance in a half bridge rectifier diode which has a significant impact on the operating point of the resonance circuit at high-frequency and high voltage conditions has been analyzed, by using the principle of the half bridge class-DE resonant rectifier with a push-pull resonant converter. The proposed scheme ensures more accurate results and provided a more systematic and feasible solution than the conventional resonant push-pull DC/DC converter analysis methodology. All of the power switches are operated under the soft switching condition. The prototype front-end ZVS push-pull converter, operate at a $62-88 \mathrm{kHz}$ variable frequency, and has a $12-\mathrm{V}_{\mathrm{DC}}$ input voltage, a $380-\mathrm{V}_{\mathrm{DC}}$ output voltage, and a rated output power of $150 \mathrm{~W}$. The designed ZCS class-DE rectifier with a ZVS push-pull resonant converter had a measured efficiency of approximately $92.97 \%$ at full power. The presented simulation and experimental results verify the analysis.

\section{ACKNOWLEDGMENT}

This paper is supported by the Department of Instrumentation and Electronics Engineering, Faculty of Engineering, King Mongkut's University of Technology North Bangkok and the Department of Electronic and Telecommunication Engineering, Faculty of Engineering, 
King Mongkut's University of Technology Thonburi, Bangkok, Thailand.

\section{REFERENCES}

[1] M.J. Ryan, W. E. Brumsickle, D.M. Divan, and R.D. Lorenz, "A new ZVS LCL-resonant push-pull DC-DC converter topology," IEEE Trans. Power Electron., Vol. 34, No. 5, pp. 1164-1174, Sep./Oct.1998.

[2] I. Boonyaroonate and S. Mori, "A new ZVCS resonant push-pull DC/DC converter topology," $17^{\text {th }}$ Annual IEEE Applied Power Electronics Conference and Exposition, Vol. 2, pp. 1097-1100, 2002.

[3] D. H. Han, Y. J. Lee, W. S. Kwon, M. A. B. Rabee, and G. H. Choe, "Improving the overall efficiency for DC/DC converter with LoV-HiC system," Journal of Power Electronics, Vol. 12, No. 3, pp. 418-428, May 2012.

[4] A. Emadi, and S.S. Williamson, "Status review of power electronic converters for fuel cell application," Journal of Power Electronics, Vol. 1, No. 2, pp. 133-144, Oct. 2001

[5] J. M. Han, B. H. Jeong, J. S. Srok, and G. H. Choe, "Analysis of PWM converter for V-I output characteristics of solar cell," Journal of Power Electronics, Vol. 1, No. 2, pp. 62-67, Oct. 2003.

[6] P. Thounthong, S. Raël, and B. Davat, "Control algorithm of fuel cell and batteries for distributed generation system," IEEE Trans. Energy Convers., Vol. 23, No. 1, pp. 148-155, Mar. 2008.

[7] P. Thounthong, B. Davat, S. Raël, and P. Sethakul, "Fuel cell high power applications," IEEE Industrial Electronics Magazine, Vol. 3, No. 1, pp. 32-46, Mar. 2009.

[8] P. Thounthong, S. Raël, and B. Davat, "Energy management of fuel cell/battery/supercapacitor hybrid power source for vehicle applications," Journal of Power Sources, Vol. 193, No. 1, pp. 376-385, Jan. 2009.

[9] B.R. Lin and L.A. Lin, "Analysis and implementation of a DC-DC converter with an active snubber," Journal of Power Electronics, Vol. 11, No. 6, pp. 779-786, Nov. 2011.

[10] M. Borage, K. V. Nagesh, M. S. Bhatia, and Sunil Tiwari, "Approximate equivalent-circuit modeling and analysis of type-II resonant immittance converters," Journal of Power Electronics, Vol. 12, No. 2, pp. 371-325, Mar. 2012.

[11] D. Han, Y. Lee, B. Jeong, and G. Choe, "Multi-level resonant push-pull converter for fuel cell system," $8^{\text {th }}$ IEEE International Conference on Power Electronics and ECCE Asia (ICPE \& ECCE), pp. 1901-1907, 2011.

[12] B. R. Lin and S. J. Shen, "Interleaved ZVS resonant converter with a parallel-series connection," Journal of Power Electronics, Vol. 12, No. 4, pp. 528-537, Jul. 2012.

[13] C. L. Chu and C. H. Li, "Analysis and design of a currentfed zero-voltage-switching and zero-current-switching CL-resonant push-pull DC-DC converter," IET Power Electronics, Vol. 2, No. 4, pp. 456 -465, Jul. 2009.

[14] J. M. Blanes, A. Garrigos, J. A. Carrasco, J. E. Marti, and E. S. Kilders, "High-efficiency regulation method for a zero-current and zero-voltage current-fed push-pull converter," IEEE Trans. Power Electron., Vol. 26, No.2, pp 444-452, Feb. 2011

[15] Z. Yao, L. Xiao, Y. Huang, and W. Yang, "Push-pull forward three-level converter for high-voltage fuel cell applications," IEEE International Conference on Electrical Machines and Systems, pp. 2698-2703, 2008.

[16] Y. Du, G. Wang, J. Wang, S. Bhattacharya, and A. Q. Huang, "Modeling of the impact of diode junction capacitance on high voltage high-frequency rectifiers based on $10 \mathrm{kV} \mathrm{SiC}$ JBS diodes," IEEE International Conference on Energy Conversion Congress and Exposition, pp. 105-111, 2010.

[17] J. H. Jung, J. M. Choi, and J. G. Kwon, "Design methodology for transformers including integrated and center-tapped structures for LLC resonant converters," Journal of Power Electronics, Vol. 9, No. 2, pp. 215-223, Mar. 2009.

[18] D. C. Hamill, "Class-DE inverters and rectifiers for DC-DC conversion," IEEE Power Electronics Specialists Conference, Vol. 1, pp. 854-860, 1996.

[19] C. Ekkaravarodome, A. Nathakaranakule, and I. Boonyaroonate, "Single-stage electronic ballast using Class-DE low- $d v / d t$ current-source driven rectifier for power-factor correction," IEEE Trans. Ind. Electron., Vol. 57, No. 10, pp. 3405-3414, Oct. 2010.

[20] C. Ekkaravarodome and K. Jirasereeamornkul, "Single-stage high-power factor electronic ballast with a symmetrical Class-DE resonant rectifier," Journal of Power Electronics, Vol. 12, No. 3, pp. 429-438, May 2012.

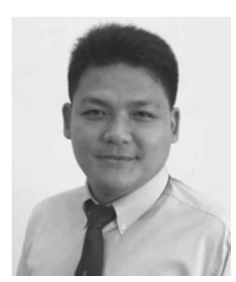

Chainarin Ekkaravarodome was born in Songkhla, Thailand, in 1981. He received his B.S. in Industrial Electrical Technology from the King Mongkut's Institute of Technology North Bangkok (KMITNB), Bangkok, Thailand, in 2003, and his M.S. and Ph.D. in Electrical Engineering and Energy Technology from the King Mongkut's University of Technology Thonburi (KMUTT), Bangkok, Thailand, in 2005 and 2009, respectively. He is currently a Lecturer with the Department of Instrumentation and Electronics Engineering, Faculty of Engineering, KMUTNB. His current research interests include electronic ballasts, power factor correction circuits, resonant rectifiers, and soft-switching power converters.

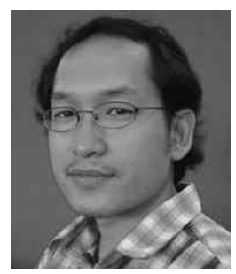

Kamon Jirasereeamornkul was born in Phuket, Thailand, in 1975. He received his B.S. and M.S. in Electrical Engineering, and his Ph.D. in Electrical and Computer Engineering from the King Mongkut's University of Technology Thonburi (KMUTT), Bangkok, Thailand, in 1997, 2001, and 2006, respectively. $\mathrm{He}$ is currently a Lecturer with the Department of Electronic and Telecommunication Engineering, Faculty of Engineering, KMUTT. His current research interests include electronic ballasts, high-frequency power converters, and power factor correction circuits. 